\title{
Smile Society: A year of student-led outreach, collaboration and adaptation
}

\author{
By Gianne Williams and Reem AlHakim
}

$\mathrm{I}$ $\mathrm{t}$ has been a tremendous pleasure to serve as co-presidents of KCL Smile Society during the last academic year. With the support and guidance of our staff president, Professor Jennifer Gallagher, we aim to improve knowledge of good health in the local community. We are determined to continue our mission and fulfil the need for oral health promotion/education and dental outreach in communities with limited access to care.

We initially planned on using social media and collaboration to supplement our outreach throughout the year and engage a wider audience. However, in light of the unexpected global crisis, we found ourselves using online mediums to continue spreading the message.

Dental community outreach is at the heart of Smile Society; throughout the year we organise a range of opportunities for our student volunteers to take part in. With a determination to improve practice and knowledge of good dental (and dietary) health we typically start the year with an induction seminar led by either Professor Gallagher or our supporting DCTs based on the Delivering better oral health guidelines. Following this we regularly email our outreach opportunities to our volunteers.

We are very proud of our committee and the projects we have worked on over the last year, which are detailed in this article.

\section{School visits (pre COVID-19)}

Whilst oral health is improving in England, tooth decay remains the most common oral disease affecting children and young people in England. Smile Society was fortunate to deliver four interactive workshops to local primary schools before lockdown began.

The visits consisted of ten dental student volunteers led by one DCT. The oral health workshops are made up of five stations: diet, tooth brushing, plaque disclosing station and a visit to the dentist station.
Following the workshops, we end the session with an interactive quiz to consolidate all the information learnt. Goodie bags are also distributed to all the students as a token of gratitude and to ensure they are kept motivated to take care of their oral hygiene.

Not only do we aim to promote discussion, healthy behaviours and diminish any fear of the dentist, we also help to empower students to use their skills to improve the oral health of the local community in which they study. These sessions have been well received by both dental students and primary school children.

\section{Homeless shelter outreach}

Armed with an artillery of oral hygiene essentials including toothpaste, toothbrushes, interdental brushes and other toiletries like body lotion, soap, and antibacterial gel, Smile Society was fortunate to visit roughly 540 guests at six homeless shelters, led by co-president Gianne Williams prior to social distancing.

During these visits, a group of seven to nine volunteers handed out oral hygiene kits, toiletries, and leaflets which inform and signpost access to NHS dental care as well as help staff and serve food at the soup kitchens. To spread some festive cheer over the Christmas period we held three volunteering events over the December period.

In response to the pandemic we also donated remaining accessible stock items to a homeless shelter hub.

\section{Christmas social}

We believe that in order to continue on this successful path we must build a bond with all Smile Soc volunteers to encourage team building. This year was the first year we piloted a Smile Society Christmas Social which featured a talk followed by an interactive Q\&A by Dr Sager Patel - an oral surgery DCT at Guy's Hospital - who was able to share his academic experiences whilst everyone was enjoying hot chocolate and homemade brownies.

We hope that in the coming academic year we are able to host more socials to inspire a sense of unity within our society.

\section{Interactive social media campaigns}

This year we introduced an interactive element to social media campaigns to engage a wider audience whilst promoting good dental hygiene practice.

Between December and April, we had four consecutive campaigns including our novel \#TreatYourTeeth, challenging our Instagram following to share habits employed over the festive period. The following month we partnered with Bart's Community Smiles (our Bart's and London society counterpart) for Sugar Awareness Week to highlight sugar content and promote healthy sugar swaps with our Shed the Sugar campaign.

One of our biggest projects this year was our \#FizzFreeFeb collaboration with Southwark Council and Sugar Smart to promote healthier alternatives to fizzy drinks. During February we posted themed daily messages and encouraged 77 Instagram users including students, staff, qualified and overseas dentists to share their 'fizzy swaps', entering our weekly competition.

We also incorporated this into our outreach, where we handed out oral hygiene kits and water during two homeless shelter visits. Our events officers did an amazing job incorporating the campaign into school visits with interactive workshops, creating assemblies and handing out calendars and posters. We also used this campaign to gain feedback from Instagram polls and from outreach which we are excited to present at the next BASCD conference.

Our final project also included themed daily messages and an interactive challenge asking users to share something that makes them smile, a fun oral health tip and 


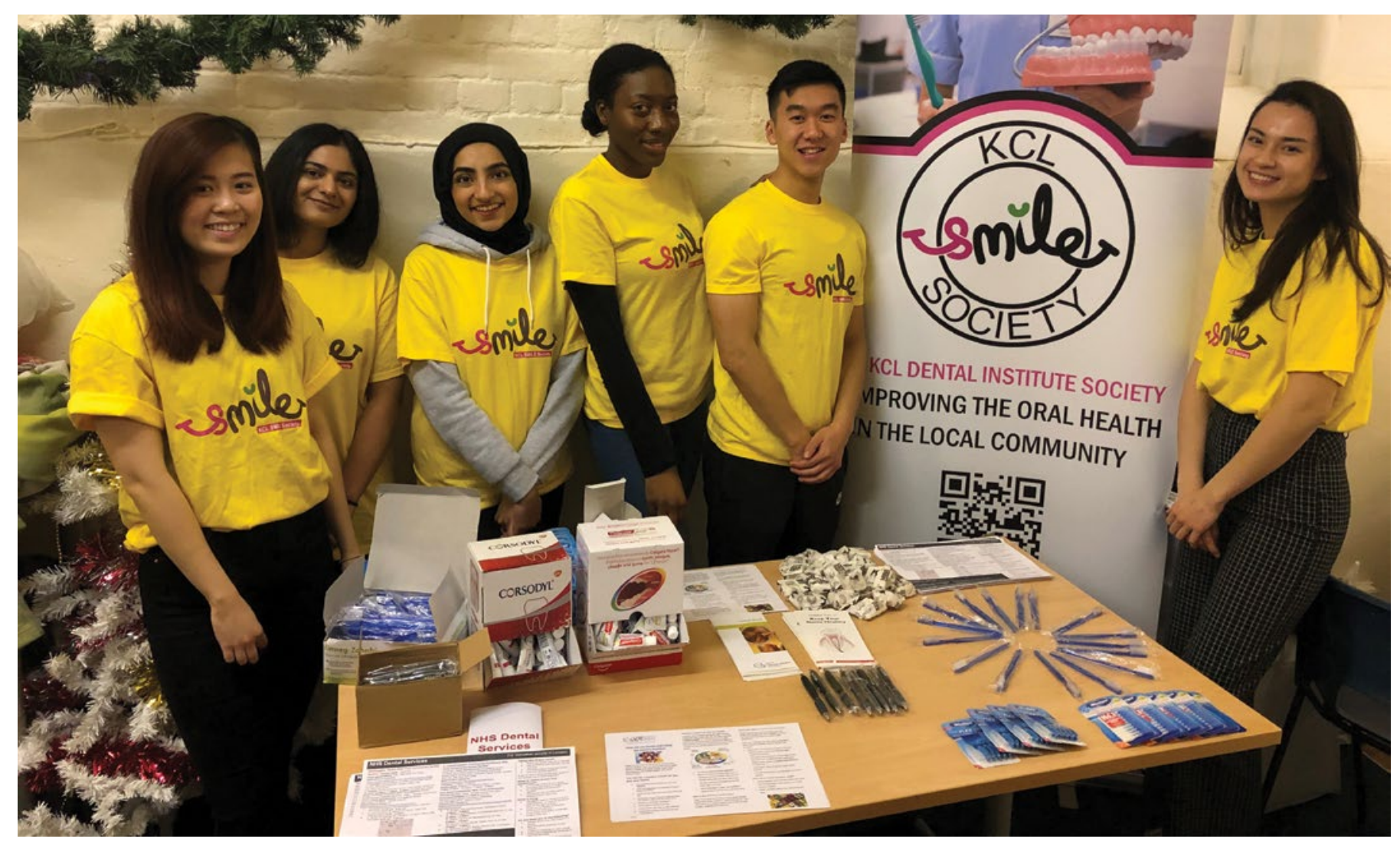

« nominate others. We would like to extend a massive thanks to our publicity officers Dona and Zahraa for helping us achieve this throughout the year.

\section{Downright Excellent}

Due to the global pandemic, Smile Society had to cancel a variety of planned events. However, that did not stop us from finding alternative solutions to continue to pursue our work and contribution to the wider community. This year, rather than visiting and hosting an oral health workshop at Downright Excellent - an organisation that provides weekly speech and language, occupational therapy and life skills sessions at the Sundial Centre in Hoxton for children and young people with Down syndrome ages 0-15 - Smile Society held online webinars instead. Our events officers, Kate and Dinah, led the activities - it was a beautiful way to stay connected with the work that we do and the feedback was very encouraging from all involved.

\section{Webinar}

This year we hosted a webinar as an alternative to what would have been our third annual conference. Entitled 'Beyond the Tooth: Giving Back and The Dental Humanitarian, we aimed to illustrate the different ways of giving back and how it can be incorporated throughout the entire dental career to make a positive impact. We also wanted to inspire students by highlighting mutual benefits of giving back such as self-fulfilment, skill development, and a widened perspective. We had over 100 people comprising national and international dental students, alumni and dental professionals sign up for the event. Our amazing speakers shared their experiences including how student challenges and outreach cultivate a mindset and skills for further outreach and entrepreneurship; student outreach experience and essential advice and skills relevant to it; and developing a moral ethos while studying and balancing dental outreach in different arenas post-graduation.

In response to the pandemic we sourced sponsorship for the webinar allowing us to distribute items including toothpaste and toothbrushes to hospitals, foodbanks and adult and child care homes.

\section{Other projects}

Each year we also host raffles at dental society dinners and host a pub quiz to fundraise for our community outreach. We also continued our children's poster competition introduced last year where participants had to create a poster on 'What is a Dental Friendly Diet and Why is it Important?'.

Throughout this year Smile Society was able to carry on amidst all the difficulties working endlessly to ensure that we can give back to the community. Our outreach also aims to provide enriching opportunities to interact/help groups they may not typically encounter, increase exposure to different areas of dentistry (such as special care, public health, community) and develop key skills alongside the dental curriculum. The feedback has been immensely positive from both students and staff on our individual events and the committee as a whole.

This year we received huge interest in our volunteering opportunities and over three times as many committee applications highlighting the student demand for taking part and coordinating outreach. Equally faculty/staff have been keen on incorporating our outreach in the curriculum. We are truly grateful for all we have accomplished this year; not only has this been a team effort, but we have received invaluable support both within and outside the (KCL) faculty. Furthermore, we have also been fortunate to collaborate with societies within and outside our university as well as local council and nationwide initiatives to promote key messages and host events. 